\title{
THE EFFECTIVENESS OR EDUCATIONAL MOO IN ENGLISH LANGUAGE CLASSROOM FOR ADVANCE LEARNERS
}

\author{
Mr. Jatin Kapadiya
}

\section{Introduction of Research Scholar}

Mr. Jatin Kapadiya has been working as an assistant professor in Alpha College of Engineering and Technology, Khatraj - Gandhi Nagar. He is pursuing PhD in English Literature from H N G University. He has 3years of experience in teaching. He has been teaching Communication skills, Soft skills and Personality development to UG and PG students since 4years. He has been presenting papers into various nationals as well as international conferences since his post graduation.

\section{Introduction:}

MOO is abbreviated as "multi-user domain, Object-Oriented." History of MOO begins with MUD (multi-user domain) as net based dungeons and dragons type games. But MOOs have evolved from these origins to become some of the Internet's most fascinating and engaging online communities which are social environment in a text based virtual reality where people gather online to chat with friends and meet new people serve the purpose of education.

It fascinates all the facility to Users (players or characters in game) which start to get accommodated in favorable place of Users own design in text based virtual reality and live in social environment by engaged in online community They can also create their own room object and programs that recreates Users imagination. Through that community Users can able to communicate with each other on real time.

Put the picture of imaginative text based virtual room of MOO. For example. "Gregor" at schMoozeUniversity created a monkey that hands out dry towels to swimmers. This program causes lines of text describing the monkey's actions to appear at regular intervals on the screens of allthe users in the same ' room'. 


\section{What do educators need to know before visiting A MOO?}

Education World offers these tips foe successful MOOing:

- Become familiar with the commands before you introduce the MOO to students.

- Consider the time zones of eachparticipating class.

- Have an alternate plan in case Internet connections are not working.

- Teach your students MOO Netiquette

- Give students plenty of limo to practice and to become familiar with the MOO before beginning a project.

- Be sure students having at least average keyboarding skills.

\section{HOW DO I GET STARTED?}

Teachers should spend several weeks becoming familiar with the technology and the psychosociological experiences associated with $\mathrm{MOO}$ before introducing it to their students. Using a MOO can be like going to a foreign country, and students need to count on their teacher to be a knowledgeable guide.

Technical considerations must be handled first: connecting to the MOO via telnet, and doing it in a user-friendly way using a MUD client program. Given that MOO is a program that runs on a remote computer; it is accessed by opening a telnet program, typing in the server name and port number, and then connecting at the log in screen of the Moo. An example: open telnet on your own machine. Type in "schmooze.hunter.cuny.edu" where the host name is requested and type in "8888" where the port number is requested. This will take you to the log in screen of schMOOze University. At that point, you can type "connect guest" or, if you already have a permanent character, you can type "connect $<$ name $><$ password $>$."

If you connect without using a MUD client, you will find that the lines of text you are writing are interrupted by incoming text from others. This can be most disconcerting. MUD clients, which can be downloaded for free, have a variety of features. The most useful is one which prevents others' text 'from interruptingyours.

\section{TO ENSURE A POSITIVE MOO EXPERIENCE FOR YOU AND YOUR STUDENTS:}

(1) Become familiar with the technology and the social dynamics of MOO use. Read web sites about educational and social MOOS and vide appropriate web addresses to your students.

(2) Work the MOO into your class schedule, planning for at least three in-lab MOO training sessions. 
(3) Facilitate in class design of tasks to be completed in the MOO for homework. Decide how these tasks will be assessed.

(4) Have your students write journal about their MOO experiences and plan for regular in-class discussions.

(5) Expect your students to teach you. Many MOO wizards are under age 15!

\section{WHAT CAN DIFFERENT KINDS OF USERS DO IN A MOO?}

Those who first connect to a MOO are calledguests. Guests have the ability to "talk", send message across the MOO by "paging." use MOOmail for sending messages, and move around the MOO. They cannot make any permanent changes in their guest "character", nor can they create objects.

Those who want a permanent character with password access need to request this.usually by sending email or MOOmail to the registrar (often the owner) of the MOO. Permanent characters can name themselves, describe themselves, and set their gender. Users come to know one another, forming friendships and sense of community. These relationships can be one of the most rewarding aspects of the MOO experience.

Builders are uses that have programming permissions for creating rooms. Exits, and objects which they can describe in any way that is consistent with the MOO's theme. They can also write customized, durable "messages" that automatically appear when certain commands are used. For example, when a user pages "MariLuz' at MundoHispano, that user will see a line of text in Spanish starting that a kangaroo puts the message in its pocket and carries it to MariLuz.

Those who learn the MOO programming language can become programmers who create more elaborate features such as Gregor's monkey. The ability to create objects "messages" and programs gives the use a sense of ownership, an outlet for creative writing and motivation to return.

The wizards are at the top of the hierarchy. They create new characters, monitor connections, teach new users, and deal with problems, often with the help of teacher administrators. They also do deeplevel programming and uniquely have access to information such as the users'e-mail addresses. In most MOOs, the arch-wizard is the one who founded the MOO, is the systems operator of the MOOserver (computer on which the MOO resides), and is considered the director and ultimate decision-maker.

\section{WHAT DIFFICULTIES CAN I EXPECT WHEN USING A MOO?}

Some teachers are uncomfortable with the loos of control over student behavior that inevitably occurs. Teachers should help students create personally meaningful tasks before the MOO is accessed, to be followed up with an assessment of outcomes. As an example, language learner might decide what topics they want to discuss with native speakers, then later report to the class what they learned, who taught a to them, and what web sites support their findings. 
Some MOO users have quite an emotional response, positive or negative, to the experiences they have. Students have been known to fall in love with or be very offended by other users. While the sense of place and permanence that is achieved on MOO cancontribute to the meaningfulness of the learning experience, some users simply have difficulty adjusting to having a virtual self (their 'character') somewhere in cyberspace. Teachers need to regularly schedule in-class discussions that focus on student reaction to MOO use.

Finally, some students come with poor keyboarding skills and others are uncomfortable with using technology in general. These students need extra attention and time to use the MOO. Pairing them up with a more technically savvy partner during MOO homework time is a good idea

\section{What is Educational MOO?}

$\mathrm{MOO}$ which is related with the field of Education ad serve the purpose of study is called Educational $\mathrm{MOO}$. An educational $\mathrm{MOO}$ has an academic theme and uses a variety of MOO communication tools such as internal e-mail, newspapers, documents, blackboards, and classroom to accommodate a variety of teaching styles.

Teachers can use these tools in harmony with the goals for the class while exploiting the nature of $\mathrm{MOO}$ as a student-centered learning environment. E.g. wwwtappedin.com

Where can educators find and explore an edu-MOO?

Not all MOOs are appropriate for students. But a few with educational themes are suitable. Education World has checked out for we think are most likely to be useful to the $\mathrm{K}$ through $\mathrm{I} 2$ educational communities.

The first, Tapped In, is a community of educators who engage in professional development programs and informal collaborative activities. This MOO's after School Online series offers teachers the opportunity to interact with special guests and to participate in professional development discussions

Tapped In also features a Student Activity Center, where teachers and students can engage in collaborative projects. To explore this MOO, click Guest Login. A friendly Help Desk guide is usually on duty and happy to show you around. Be sure to read the guidelines for use as well.

Diversity University, the first MOO to be designed specifically for classroom use. The Main Campus is a real time, virtual reality educational environment that's Internet accessible. It allows the addition of graphics, sound, movies, and textual objects. To explore the MOO, follow the directions for login. DU is used primarily by those in higher education, but it offers the basic commands in its free Classes in MOOing,

Rainbow MOO, a division of DU Main, allows K through 12 teachers so bring students online for interactive experiences. 
'(Rainbow M00) was originally started to provide a safer, more controlled environment than DU Main could be for children," Michel Lavondes, Arch Wizard of Rainbow MOO, told Education World. For that reason, Rainbow allows no guests and has taken care that class experience no interference. Student visitors must be involved in a MOO project under the direct supervision of an adult. Teachers must complete a training program in basic $\mathrm{MOO}$ usage — provided by the $\mathrm{MOO}$ - before bringing students.

"So far, (Rainbow M00) has been used mostly for class activities for students in grades 7 through 9 and for discussions between Canadianand Russian children," stated Lavondes.

SchMOOze University was created especially for student studying English as a second language. Students practice language skills through individual and group conversations. Access to language games and on online dictionary it also provided. Anyone interested incross-cultural communication is welcome. There's also a Collaborative MOO Project that can be used with students in grades 9 through 12.

\section{How do educators use the MOO?}

How can students from California collaborate with students from Brazil? For teacher Linda Ullah, from Edenvale Elementary in San jose, California, a MOO was the answer.

Ullah used Tapped In as a meeting place where students and teachers from California and Brazil worked together on projects and got to know one another. The teachers also used the MOO to preplan the discussion questions for student sessions. Planning with teachers who were separated by thousands of miles was made easy by creating a virtual office space for meetings. The teachers could leave notes or share the whiteboard during online discussions.

'It wasn't just any MOO ... I had the knowledge that Tapped In is a safe environment and that there is a facilitator who is also an educator," Ullah told Education World. "(The students) loved it and took to it naturally. Comfort was not a problem for either my kids (grades 3 through 6) or the Brazilian kids (high school level). They seemed to adapt easily," said Ullah.

From the project's transcripts,Water Pollution in Brazil and California. It's obvious that students helped one another, followed 'Netiquette," discussed the topic of water pollution in their communities, and had fun in the process.

In addition to the educational benefits for her students, Ullah uses Tapped In for her own professional development. "I love the ability to meet with other teachers to discuss curriculum, innovative teaching practices, assessment, copyright, and ethics" said Ullah "It has made me a better educator.'

Education World writer Walter McKenzie has also used the MOO successfully with students. While working on the President's project, he and middle school teacher 
Andrea Myers used the synchronous environment of the MOO to give students the opportunity to collaborate on researching Thomas Jefferson and constructing a Web page. Each student was provided with an individual name and password, which allowed him or her to work in the Student Activities Center of Tapped In.

McKenzie and Myers arranged students into small groups that worked in individual study areas. A tape recorder recorded the sessions, so teachers were free to circulate and facilitate discussion. McKenzie took care of the technical questions, and Myers facilitated the discussion and kept everyone on track. "It was great!" said McKenzie. "We got more accomplished in one session than we ever accomplished asynchronously.'

Michael Hutchinson, a social science teacher at Lincoln High School in Vincennes. Indiana took his freshmen students to the MOO to participate in a Student Online Civil RIGHT FORUM with students from Thurgood Marshall High School in San Francisco. Students prepared for the font by creating a Web page or a PowerPoint presentation on a minority group. Based on that experience, Hutchinson would prepare for future MOO projects slightly differently.

"I would have the students more prepared and have my kids provided a more in-depth perspective," Hutchinson told Education World.

"My experience [with the MOO] his been much greater in professional development than in bringing students in." Hutchinson continued. As member of Tapped In, one of the more popular MOOs for the educational community, Hutchinson often hosts sessions that provide an opportunity to show the site to anyone who drops by.

"We can project notes and text messages we create ourselves, and we also project Web sites that visitors can see on their browsers at home," Hutchinson said. "Using a recorder, we can maintain a record of all the activity in a MOO room." Hutchinson sees the value of tapped in as "giving teachers a great sense of community that is just as important as the flow of information."

\section{What do educators need to know before visiting a MOO?}

Education World offers these tips for successful MOOing:

- Become familiar with the commands before you Introduce the MOO to students.

- Consider the time zones of each participating class.

- Have an alternate plan in case Internet connections are not working

- Teach your students MOO Netiquette.

- Give students plenty of time to practice and to become familiar with the MOO

Before beginning a project 
- Be sure of students having at least average keyboarding skills.

Uses of Educational MOO:-

$=>$..........Face to face interaction

$=>$......... Videoconferencing

$=>$........ Synchoronous interaction in a text-based virtual world, "Tapped In"

$=>$........ "Groupware" that incorporates a shared deign-space (using Microsoft NetMeeting)

$=>\ldots \ldots \ldots .$. Asynchronous discussions [http://Aownhall.gmu.edu]: and

$=>\ldots \ldots \ldots . . .$. Web sites structured around an ongoing interaction or experience.

\section{WHERE CAN I FIND MORE INFORMATION ON EDUCATIONAL MOOS?}

-How to connect to a MUSK/MOO/MUD: telnet and client programshttp://fly.ccs.yorku.ca/mush/con-intro.html

-Chaco Communications-http://www.chaco.com/ (download the excellent Pueblo MUD client here)

-Educational VR (MUD) sub-page- http://tecfa.unige.ch/edu-comp/WWW-VL/edu VR-page.html

-DU journal of educational moos---http://tecfa.unige.ch/edu-comp/DUJVRE/vo11/DUJVRE.1.1.text

-Journal of MUD Research- http://mellers1.psych.berkeley.edu/ jomr/

MOO teacher's Tip sheet—http://www.daedalus.com/net/MOOTIPS.html

-MOOing in a foreign language: how, Why, and who?http://web.syr.edu/lmturbee/iteehtm.html

--MUDs, MOOs-,MUSHs---http://www.itp.berkeley.edu thorne/M00.html

---NETEACH-L. MOO Sessions Information----

http://spot.colorado.edu/ youngerg/moodates.html

---freya's list o' moos—http://www.teleport.com/ autumn/moo.html

---The palace,Inc. Virtual World Chat Software-http://www.thepalace.com/index.html (2-D MOOlike environment) 


\section{Bibliography}

Turbee.L. (1 995). 'MundoHispano: A Text-Based Virtual Environment for Learners and Native Speakers of Spanish." In: Mark Warschauer, (Ed.). "Virtual Connections "(pp. 233-234). Manoa, $\mathrm{HI}$ : Second Language Teaching and Curriculum Center, University of Hawaii at Manoa.

Turbee, L. (1995). "What can we do In a MOO?: Suggestions for Language Teachers." In: Mark Warschauer. (Ed.). "Virtual Connections" (pp. 235-238). Manoa, HI: Second Language Teaching and Curriculum Center, University of Hawaiii at Manoa at Manoa.

Warschauer, M., Turbee, L.,\& Roberts.B. (1996).Computer learning networks and student empowerment "SYSTEM."24(1). 1-14. (Ej527 752)

\section{Mr. Jatin Kapadiya Assistant Professor Email: kapadiyajatin@gmail.com}

